\title{
Erratum to: Mobile image sensors for object detection using color segmentation
}

\author{
Sang-Hoon Kim • Young-Sik Jeong
}

Published online: 14 June 2013

(C) Springer Science+Business Media New York 2013

Erratum to: Cluster Comput

DOI 10.1007/s10586-013-0267-6

Dongkuk University should be spelled Dongguk University.

The online version of the original article can be found under doi:10.1007/s 10586-013-0267-6.

S.-H. Kim ( $₫)$

Dept. of Electrical, Electronic and Control Engineering,

Hankyong National University, Anseong, Korea

e-mail: kimsh@hknu.ac.kr

Y.-S. Jeong

Dept. of Multimedia Engineering, Dongkuk University, Seoul,

Korea 